\title{
The Methods of Terminal Capacity Analysis
}

\author{
Roman Vokáč \\ Department of Air Transport, \\ Faculty of Transportation Sciences, \\ Czech Technical University in Prague \\ Horská 3, Praha 2, 128 03, Czech Republic \\ e-mail: vokacrom@fd.cvut.cz
}

\author{
Tomáš Lipták \\ Department of Air Transport, \\ Faculty of Transportation Sciences, \\ Czech Technical University in Prague \\ Horská 3, Praha 2, 128 03, Czech Republic \\ e-mail: liptatom@fd.cvut.cz
}

\author{
Milan Lánský \\ Department of Air Transport, \\ Faculty of Transportation Sciences, \\ Czech Technical University in Prague \\ Horská 3, Praha 2, 128 03, Czech Republic \\ e-mail: lanskmi1@fd.cvut.cz@fd.cvut.cz
}

\begin{abstract}
The capacity is a critical issue at many airports today. There are tools for capacity examining and management. But terminal operations are comprehensive and complex and some methods are not suitable. This paper deals with two basic approaches in methods of analyzing the terminal capacity.
\end{abstract}

\section{Keywords- Capacity, Kendall notation, Queuing theory}

\section{INTRODUCTION}

The continuous growth of air traffic leads to problematic issues in the field of air transport capacity. An insufficient capacity in the previous periods limits the development of current activities. Limitations arise on the passenger's arrival at the airport, at check-in desks, security controls, waiting rooms and so on. These issues affect passengers directly. That is the reason why passengers perceive them more than other constraints. The passenger satisfaction and airport operation efficiency have also impact on the level of service, demand calculation [1], airport's earnings and so on. It is necessary to understand the issues of capacity and examine them in greater detail.

\section{CAPACITY - A KEY ISSUE}

The capacity expresses the ability to absorb something. Generally, we distinguish between static and dynamic capacity. Static capacity is the maximum number of people or objects in the monitored area.

For example it is appropriate to monitor the capacity of parking spaces, passenger's waiting rooms or airspace capacity. The static capacity gives information about the state of terminal capacity, as well as airspace capacity. Information can illustrate the state of terminal capacity (2,000 passengers of total capacity $3,500-57 \%$ occupancy).
A dynamic capacity is also an important parameter to be considered. It deals with questions such as how many vehicles can arrive at the airport per hour, the number of checked-in passengers in ten minutes, how many planes can land during the day, and so on. Dynamic capacity is calculated as the number of passengers (airplanes) expressing the occurrence of the monitored phenomenon per time unit.

Only the mutual and adequate combination of the static and dynamic capacity leads to smooth operation of air traffic. Achieving maximum of the planned capacity in individual areas or even its exceeding has a very negative impact on the customer satisfaction or on aviation safety.

The following figure (Figure 1) shows an interrelation between the static and dynamic capacity. An illustrative example: there are five trains arriving every fifteen minutes at the airport. Each train brings 300 passengers whereas one checkin desk will handle 40 passengers per hour. The figure shows the variation of the average number of waiting passengers depending on the number of check-in counters.

In this example, the required minimum static terminal capacity varies in the range from 500 to 1,500 passengers, depending on the dynamic capacity. For optimal analysis and assessment of the situation in the context of aviation, it is suitable to use queuing theory.

\section{THE IMPORTANCE OF QUEUING THEORY IN AVIATION}

\section{A. What is queuing theory about?}

Queuing theory is a part of applied mathematics. It is a study of system operations where the recurrence of a sequence of operations is present. The emergence time and the time of the occurrence of such operations are usually random. The aim is to specify dependencies between the entry requirement character, 
lines productivity and operation efficiency. For this purpose, it is appropriate to define the basic terms that are relevant to this area. Those can be found in the standard books written on this topic, see e.g. [2, 3].

The dependence of the number of waiting passengers on the number of check-in desks

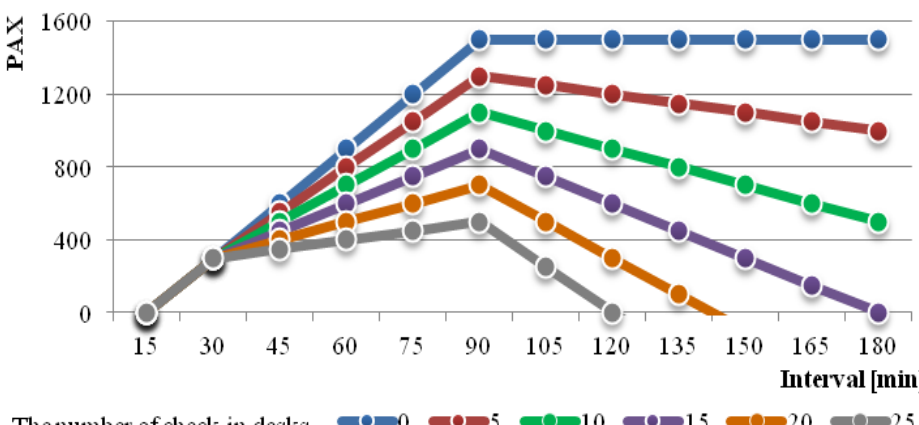

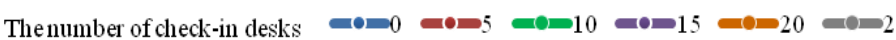

Figure 1. The dependence of the number of waiting passengers on the number of check-in counters

\section{B. Basic terms}

Basic queuing model (Figure 2) is characterized by the following terms. The arrival process of customers describes the laws of the origin and arrival of a new requirement. The arrival rate $(\lambda)$ is equal to the mean value of the number of customers entering per time. Arrival times are usually independent and have a common distribution (for example customers arrive according to a Poisson stream). The service times are usually independent and identically distributed. The service times are commonly deterministic or exponentially distributed. The service rate $(\mu)$ equals to the mean value referring to the number of customers served by one line per time.

Service Process

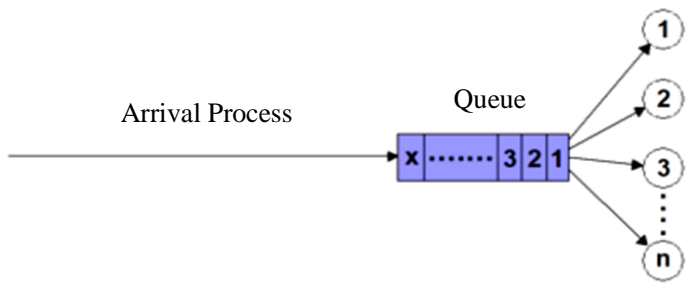

Figure 2. The basic queuing theory mode

The usage may be shown at check-in counters. For example, there are 640 incoming passengers per hour. The arrival rate $(\lambda)$ is 640 PAX per hour. The average number of handled passengers at one check-in counter is 40 per hour. There are 18 check-in counters. The service rate $(\mu)$ is 720 PAX per hour. Another important value is the utilization rate $(\rho)$. The utilization rate is calculated by dividing the arrival rate by the service rate. For this example, the result for the service rate is approximately 0.89 (i.e. $89 \%)$

Queue discipline defines the order in which requests are delivered to the server. Common orders are FIFO (First In -First Out, i.e. in order of arrival), LIFO (Last In - First Out), P-FIFO (FIFO with Priorities), SIRO (Search In Random
Order), SJF (Shortest Job First, i.e. shortest processing time first).

Kendall notation characterizes a range of queuing models. Kendall proposed describing the queuing models by using three factors in 1953 [4]. Nowadays, after its enlargement, we use five symbols for classification $-\mathrm{A} / \mathrm{B} / \mathrm{C} / \mathrm{D} / \mathrm{E}$. The letter A specifies the arrival process (the time distribution between arrivals (new requirements) to the queue) and $\mathrm{B}$ describes the service time distribution. Letter $C$ specifies the number of servers, $D$ is the capacity of the queue and $\mathrm{E}$ is the queuing discipline.

In case of $A$ or $B$ the letter $G$ is used for general distribution, $\mathrm{M}$ for the exponential distribution, $\mathrm{D}$ for deterministic times, etc.

\section{The Queuing theory in passenger terminal operations}

The capacity is a widely discussed issues, see e.g. [5, 6, 7]. The following example illustrates the usage of queuing theory in passenger terminal operations. Let us consider now an airplane with a capacity of 140 passengers. There are 2 check-in counters in the terminal. Each counter is able to handle $60 \mathrm{PAX}$ per hour in average with the exponential service time distribution. In this case, the checking-in process ( 2 hours) is divided into six sections, each lasting twenty minutes. The passengers are arriving according to a Poisson stream while the distribution of the number of arriving passengers for the time section is: (1) $4.3 \%$, (2) $14.3 \%$, (3) $27.1 \%$, (4) $25.7 \%$, (5) $21.4 \%$ and (6) $7.2 \%$ The system is stable for each section. The Kendall's notation, for this instance, is $\mathrm{M} / \mathrm{M} / 2 / \infty /$ FIFO. In order to calculate an average queue length $\mathrm{E}[\mathrm{F}]$, the following formulas are used.

$$
\begin{gathered}
\boldsymbol{p}_{0}=\left(\sum_{k=0}^{n-1} \rho^{k} \frac{1}{k !}+\frac{n(\rho)^{n}}{n !(n-\rho)}\right)^{-1} \\
\boldsymbol{p}_{\boldsymbol{n}}=p_{0} \rho^{n} \frac{1}{n !} \\
\boldsymbol{E}[\boldsymbol{F}]=\frac{p_{n} \rho_{n}}{\left(1-\rho_{n}\right)^{2}}
\end{gathered}
$$

The figure (Figure 3) shows the results of the calculation. The average number of customers in the queue is highest in the third period when reaching nearly 18 waiting passengers.

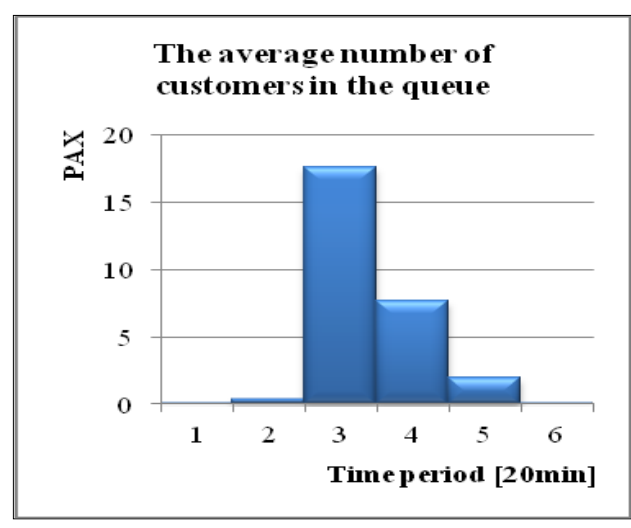

Figure 3. The average number of customers in the queue 
To deal with the problems of the queuing theory, there are two basic methods - analytic method (formulas) and simulations.

In the previous section, there was shown an example of solving the problem by the analytical method. The main advantages of this method are fast results and insight. The disadvantage is a considerable limitation of using this method. It is often inaccurate or inapplicable. If the processes do not meet the primary assumptions, the simulation methods have to be used so as to obtain the results.

In the simulation, the system is replaced by a model with the same characteristics. The simulation methods are known for the broad applicability, accurate and realistic modeling. The advantage is in possibility of studying the dynamics of the entire system and the ability to create non-standard situation models. The disadvantage is in the need for huge amount of input data. Consequently, the process of creating the simulation model may be very slow and expensive. The appropriateness of using simulation models for passenger terminal operation, however, is indisputable.

The following figure (Figure 4) shows a basic check-in simulation model for two counters.

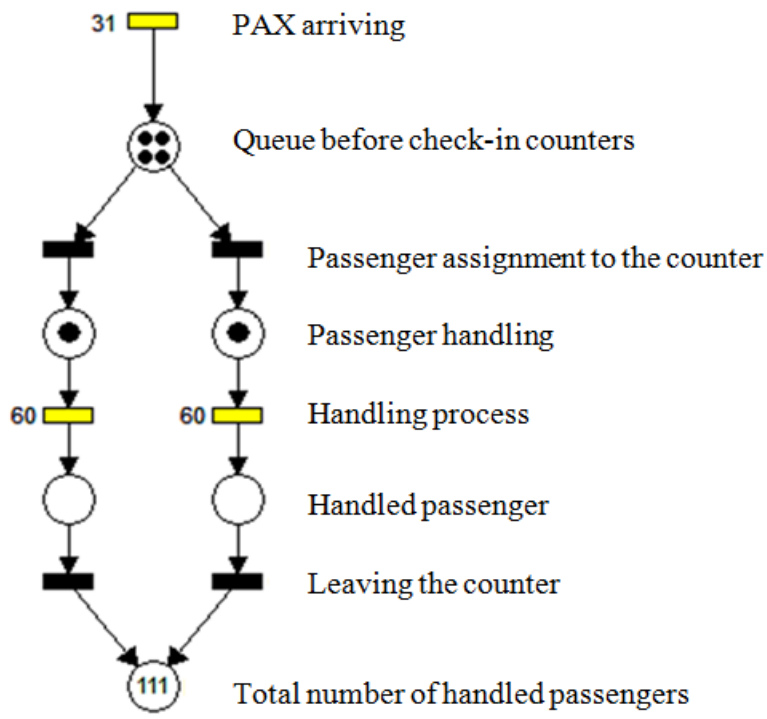

Figure 4. The basic check-in simulation model

The model is based on Petri nets and although it has so simple configuration, it allows obtaining the first information. Petri nets can be used not only for creating simulations, but also for easy description of the system. Results can be deterministic, which corresponds to a mathematical equation, or stochastic. To obtain stochastic results, the system must be described by the probability.

After the extension of the model and determination of all important characteristics of the system, the number of checkedin passengers can be determined. In comparison with the analysis method, the stochastic simulation always provides a different result (Figure 5).

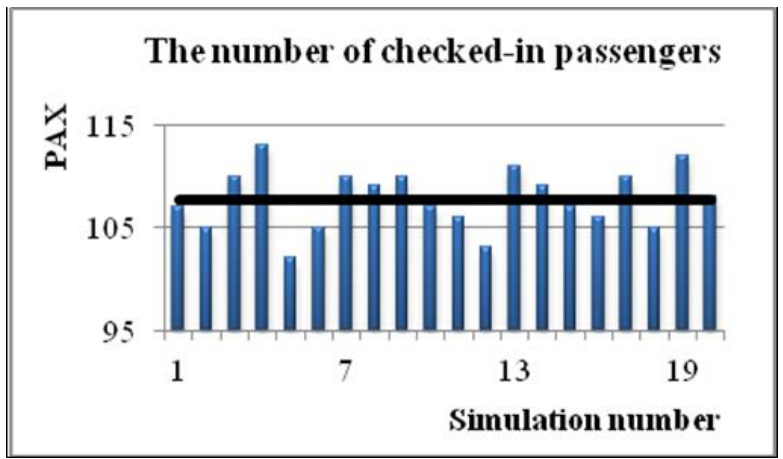

Figure 5. The number of checked-in passengers

For examining the entire process of handling passengers it is appropriate to create a complex simulation model by using specialized software designed for this purpose. This specialized software works on the basis of Monte Carlo method which is useful when it is difficult or impossible to use other mathematical methods.

\section{CONCLUSION}

As it was described in the article, the aviation systems are considerably complex and difficult. It is not convenient to use analytical methods for solving problems related to the capacity. In contrast, using of the simulation methods is a suitable tool for solving problems related to the capacity. The simulation methods thus enable the analysis of the current system state as well as an effective forecasting. The authors plan to continue with solving the mentioned issues through creating of simulation models.

\section{REFERENCES}

[1] ENDRIZALOVÁ, Eva, Vladimír Němec. Demand for Air Travel. MAD - Magazine of Aviation Development. 2014, vol. 2, no. 12, p. 15-17. ISSN 1805-7578

[2] KLEINROCK, Leonard. Queueing Systems. New York: J. Wiley, 1975, xvii, 417 s. A Wiley-Interscience Publication. ISBN 0-47149110-1.

[3] ROSS, Sheldon M. Introduction to probability models. 10th ed. Boston: Academic Press, c2010, xv, 784 p. ISBN 0123756863

[4] KENDALL, David G. Stochastic Processes Occurring in the Theory of Queues and their Analysis by the Method of the Imbedded Markov Chain. The Annals of Mathematical Statistics [online]. 1953, 24(3): 338-354 [cit. 2015-11-28]. DOI: 10.1214/aoms/1177728975. ISSN 0003-4851. Dostupné z: http://projecteuclid.org/euclid.aoms/1177728975

[5] STOLLETZ, Raik. Analysis of passenger queues at airport terminals.Research in Transportation Business \& Management [online] 2011,1(1): 144-149 [cit. 2015-11-28]. DOI: 10.1016/j.rtbm.2011.06.012. ISSN 22105395. Dostupné z: http://linkinghub.elsevier.com/retrieve/pii/S2210539511000198

[6] NIE, Xiaofeng, Gautam PARAB, Rajan BATTA a Li LIN. Simulationbased Selectee Lane queueing design for passenger checkpoint screening. European Journal of Operational Research [online]. 2012 219(1), 146-155 [cit. 2016-01-13]. DOI: 10.1016/j.ejor.2011.12.012. ISSN 03772217. Dostupné z:

http://linkinghub.elsevier.com/retrieve/pii/S0377221711010897 
[7] MELNÍKOVÁ, L, Patrik PADARAS, Stanislav SZABO. Využitie kapacity slovenských medzinárodných letísk. eXclusive Journal. 2014, roč. 2 , č. 4 , s. 147-156. 